\title{
Effect of an intervention on antibiotic prescription control for respiratory diseases: a systematic review of randomized controlled trials
}

Chang Yue ( $4567401 @ q q . c o m$ )

Guizhou Medical University https://orcid.org/0000-0003-1048-6932

Zhezhe Cui

Guangxi Zhuang Autonomous Region Center for Disease Control and Prevention

Guanghong Yang

Guizhou Medical University

Xun $\mathrm{He}$

Guizhou Medical University

Lei Wang

Guizhou Provincial Health Commission

Zhang Xin

Guizhou Medical University

Lei Tang

Guizhou Medical University

\section{Research}

Keywords: Randomized controlled trial, Antibiotic prescriptions, Feedback intervention, Systematic evaluation, Meta-analysis

Posted Date: February 12th, 2021

DOI: https://doi.org/10.21203/rs.3.rs-76757/v7

License: (c) (i) This work is licensed under a Creative Commons Attribution 4.0 International License. Read Full License 


\section{Abstract}

Background The global health system is improperly using antibiotics, particularly in the treatment of respiratory diseases. We aimed to examine the effectiveness of implementing a unifaceted or multifaceted intervention for unreasonable antibiotic prescriptions. Methods Relevant literature published in the databases of Pubmed, Embase, Science Direct, Cochrane Central Register of Controlled Trials (CENTRAL), Chinese Journal Full-text (CNKI) and Wanfang was searched. Data were independently filtered and extracted by two reviewers based on a pre-designed inclusion and exclusion criteria. The Cochrane collaborative bias risk tool was used to evaluate the quality of the included studies. Results A total of 1,074 relevant studies were obtained of which 69 were included in the systematic review. Fifty-nine studies reported positive results, that is, the primary results in the intervention groups were superior to those in the control groups. The remaining 10 studies had negative or partially negative results. In 22 studies the outcome variable was the antibiotic prescription rate with detailed reports of the number of prescriptions being further analyzed, of which 19 involved educational interventions for doctors, including: (1) Online training using email, web pages and webinar, (2) Antibiotic guidelines for information dissemination measures by email, postal or telephone reminder, (3) Training doctors in communication skills, (4) Short-term interactive educational seminars, and (5) Short-term field training sessions. Seventeen studies of interventions for health care workers also included: (6) Regular or irregular assessment/audit of antibiotic prescriptions, (7) Prescription recommendations from experts and peers delivered at a meeting or online, (8) Publicly reporting on doctors' antibiotic usage to patients, hospital administrators, and health authorities, (9) Monitoring/feedback prescribing behavior to general practices by email or poster, and (10) Studies involving patients and their families ( $\mathrm{n}=10$ ). Seventeen studies were rated as having a low risk of bias while five were rated as having a high risk of bias. Conclusion Implementing multiple interventions in health care institutions can effectively reduce antibiotic prescription rates. Adding multiple feedback interventions to educational interventions may be a more reasonable control method. Registrations: This systematic review was registered in PROSPERO, registration number: CRD42020192560.

\section{Background}

The discovery of antibacterial drugs is an important milestone in the history of human medical science. The emergence of antibiotics (ATB) has changed the outcome of infections, thereby extending people's life expectancy ${ }^{1}$. However, in the past decade, $50 \%$ of the world's ATB prescriptions have been misused to treat coughs and colds, and many of these prescriptions have no indications for ATB use ${ }^{2}$. Globally, over 700,000 people died in 2020 as a result of overuse and misuse of ATB and this figure could rise to 10 million by 2050 , surpassing cancer as the leading cause of death ${ }^{3,4}$.

Previous studies have shown that implementing interventions with doctors can effectively reduce antibiotic misuse and thus curb antibiotic resistance ${ }^{5-7}$. Feedback interventions are the act of providing knowledge of the results of a behavior or performance to an individual ${ }^{8}$. The intervention strategy for antibiotic prescription began at the end of the 20th century when Janet and colleagues first implemented an education and feedback intervention in primary care hospitals of Canada and achieved remarkable results ${ }^{9}$. Since then, similar feedback interventions have been implemented in many countries and have initially formed some effective antibiotic prescription feedback intervention strategies, including individual feedback and educational interventions, educational seminar and training, audit and feedback interventions, and peer comparison feedback intervention ${ }^{10-14}$.

To further confirm the effectiveness of various feedback interventions on antibiotic prescription misuse control, we used the Cochrane systematic review and meta-analysis methods to evaluate the published results of relevant randomized controlled trials (RCTs) to provide a reference for relevant decision-makers. Antibiotic prescription rate is the main outcome indicator of feedback intervention to control antibiotic prescription.

\section{Materials And Methods}

\section{Protocol and registration}

This systematic review was conducted using the PRISMA reporting guidelines ${ }^{15}$. And registered in PROSPERO, registration number: CRD42020192560.

\section{Inclusion criteria}

The inclusion criteria of this study were based on the full-text information available in the English and Chinese literature databases, and also included the following:

(1) Random sampling;

(2) RCTs of intervention and control groups with measurements collected both before and after the intervention. Due to the limited literature in this research field, there was no requirement that every study be strictly randomized;

(3) Intervention targets were medical personnel with qualifications to prescribe medicines in medical and health institutions;

(4) The interventions were clearly described;

(5) There were detailed reports on the number of prescriptions included in the analysis or indirect speculation from the literature;

(6) The outcome variable was the antibiotic prescription rate (defined as the number of antibiotic prescriptions / total prescriptions $\times 100 \%$ );

(7) The study object was infectious diseases such as the respiratory system.

\section{Exclusion criteria}


(1) Cross-sectional studies $\bigotimes$

(2) System reviews and letters;

(3) Duplicate studies.

\section{Selection strategy and information sources}

A systematic literature search was conducted in PubMed, Google Scholar, Cochrane Central Register of Controlled Trials (CENTRAL), Science Direct, Proquest, Chinese Journal Full-text (CNKI) and Wanfang database. The search period was from the time of construction of the database to February 1, 2020. We collected published English and Chinese studies evaluating the effectiveness of antibiotic prescription interventions. Keywords search terms used included ("Antibiotic prescription" or "Antimicrobial prescription") and ("Intervention" or "Feedback intervention") and "Hospital". Data were independently filtered and extracted based on the pre-designed inclusion and exclusion criteria.

\section{Risk of bias assessment}

The first two authors (YC, ZZC) read the abstracts of all uncertain studies and the full-text of all studies that were still uncertain. A final agreement to include or exclude the studies was done after discussion of the discrepancies. The risk of bias in the included studies was independently assessed according to the "Cochrane systematic reviewer's manual"16. There are 7 items in the criteria. The bias risk assessment scoring criteria for each study were: "low risk" when all items were rated "low" or one or two of them "unclear". If one or more items were rated "high" and more than one "unclear", it was rated as "high risk". RevMan 5.3 software was used to show the risk of biased results. Funnel charts are shown to evaluate publication bias.

\section{Meta-analysis}

We conducted a meta-analysis of all the studies selected for the systematic review, and the study objects were the medical records of the intervention group and the control group after the intervention. The risk difference (RD) of antibiotic prescription rate of the two groups was combined, and the combined effect value and $95 \%$ confidence interval $(\mathrm{Cl})$ were calculated. The $\mathrm{T}$ test and Chi-square test statistics were used to assess the level of heterogeneity between the results $(\mathrm{a} \otimes 0.05)$, and a fixed-effects model $(P>0.05)$ or a random-effects model $(P \leq 0.05)$ was consequently used. If there was still significant heterogeneity in the research results, a subgroup analysis or a descriptive analysis was presented. RevMan 5.3 software was used for meta-analysis.

\section{Results}

The search and selection process is shown in Fig. 1. A total of 404 relevant studies were obtained, of which 235 were excluded after reading the title and abstract. The remaining 169 studies were further screened by reading the full-text, of which 160 were excluded: 114 were treatment or drug intervention trials, 15 were antibiotic cost-benefit analysis studies, 20 were systematic reviews or cohort studies such as non-RCTs, 4 were duplicate studies, and in 7 studies the full-text could not be accessed. Finally, 9 studies were included.

The characteristics of the included studies are shown in Table 1. A total of 9 RCTs were included in the study, including 1 published in Chinese and 8 in English. The 9 studies involved a total of 238,196 prescriptions from 7 countries: China, the United States, England, Spain, Norway, Germany, and France (103,370 in the intervention group and 134,826 in the control group). Five studies were designed using cluster sampling, 7 were interventions implemented at a primary hospital, 8 involved respiratory tract infections (RTIs) as the target infection, 3 mentioned that the duration of the intervention was more than 1 year, while 2 mentioned that the duration of the intervention was less than 1 year. 
Table 1

Basic characteristics of the studies

\begin{tabular}{|c|c|c|c|c|c|c|c|c|c|}
\hline \multirow[t]{2}{*}{ Author } & \multirow[t]{2}{*}{ Year } & \multirow[t]{2}{*}{ Country } & \multicolumn{2}{|c|}{$\begin{array}{l}\text { Sample size included in the } \\
\text { study } \\
\text { (antibiotic prescriptions / total } \\
\text { prescriptions) }\end{array}$} & \multirow[t]{2}{*}{$\begin{array}{l}\text { Research } \\
\text { design }\end{array}$} & \multirow[t]{2}{*}{$\begin{array}{l}\text { Hospital } \\
\text { type }\end{array}$} & \multirow[t]{2}{*}{ Intervention object } & \multirow[t]{2}{*}{$\begin{array}{l}\text { Duration of } \\
\text { intervention }\end{array}$} & \multirow[t]{2}{*}{$\begin{array}{l}\text { Bias } \\
\text { risk }\end{array}$} \\
\hline & & & $\begin{array}{l}\text { Intervention } \\
\text { group }\end{array}$ & Control group & & & & & \\
\hline $\begin{array}{l}\text { Dekker A.R.J, } \\
\text { et al }{ }^{17}\end{array}$ & 2018 & England & $100 / 475$ & $175 / 531$ & $\begin{array}{l}\text { Cluster } \\
\text { sampling }\end{array}$ & $\begin{array}{l}\text { Primary } \\
\text { care } \\
\text { hospital }\end{array}$ & $\begin{array}{l}\text { General practitioners and } \\
\text { patients' families }\end{array}$ & Unclear & low \\
\hline $\begin{array}{l}\text { Altiner A, et } \\
a l^{18}\end{array}$ & 2007 & Germany & $289 / 787$ & $596 / 920$ & $\begin{array}{l}\text { Cluster } \\
\text { sampling }\end{array}$ & $\begin{array}{l}\text { Primary } \\
\text { care } \\
\text { hospital }\end{array}$ & $\begin{array}{l}\text { General practitioners and } \\
\text { patients }\end{array}$ & 1 months & low \\
\hline $\begin{array}{l}\text { Llor C, et al } \\
19\end{array}$ & 2018 & Spain & $1200 / 5381$ & $1707 / 5578$ & $\begin{array}{l}\text { Random } \\
\text { allocation }\end{array}$ & $\begin{array}{l}\text { Primary } \\
\text { care } \\
\text { hospital }\end{array}$ & General practitioner & Unclear & high \\
\hline $\begin{array}{l}\text { Meeker D, et } \\
\text { al }{ }^{20}\end{array}$ & 2019 & USA & 2759/16959 & $3541 / 14753$ & $\begin{array}{l}\text { Cluster } \\
\text { sampling }\end{array}$ & $\begin{array}{l}\text { Primary } \\
\text { care } \\
\text { hospital }\end{array}$ & Clinician & 18 months & low \\
\hline $\begin{array}{l}\text { Ferrat } E \text {, et al } \\
21\end{array}$ & 2016 & France & $9916 / 70830$ & $17708 / 106036$ & $\begin{array}{l}\text { Random } \\
\text { allocation }\end{array}$ & $\begin{array}{l}\text { Suburban } \\
\text { hospital }\end{array}$ & General practitioner & 2 days & low \\
\hline $\begin{array}{l}\text { Metlay J.P, et } \\
\text { al }{ }^{22}\end{array}$ & 2007 & USA & $1263 / 3006$ & $1263 / 2659$ & $\begin{array}{l}\text { Cluster } \\
\text { sampling }\end{array}$ & $\begin{array}{l}\text { Public } \\
\text { hospitals }\end{array}$ & Clinicians and patients & 1 days & low \\
\hline $\begin{array}{l}\text { Dyrkorn } \mathrm{R} \text {, et } \\
\text { al }^{23}\end{array}$ & 2016 & Norway & $288 / 698$ & $213 / 514$ & $\begin{array}{l}\text { Random } \\
\text { allocation }\end{array}$ & $\begin{array}{l}\text { Primary } \\
\text { care } \\
\text { hospital }\end{array}$ & General practitioner & $\begin{array}{l}2 \text { years, } \\
4 \text { months. }\end{array}$ & high \\
\hline $\begin{array}{l}\text { Wei XL, et al } \\
24\end{array}$ & 2018 & China & $2748 / 5084$ & $2772 / 3685$ & $\begin{array}{l}\text { Cluster } \\
\text { sampling }\end{array}$ & $\begin{array}{l}\text { Township } \\
\text { hospitals }\end{array}$ & Doctor & $\begin{array}{l}1 \text { year, } \\
6 \text { months. }\end{array}$ & low \\
\hline$\underset{25}{\text { Qiu JG, et al }}$ & 2016 & China & $107 / 150$ & $143 / 150$ & $\begin{array}{l}\text { Random } \\
\text { allocation }\end{array}$ & $\begin{array}{l}\text { Grade two } \\
\text { hospital }\end{array}$ & Doctor & Unclear & high \\
\hline
\end{tabular}

\section{Interventions of included studies}

Table 2 shows the categories of interventions included in the studies. Eight of the 9 studies involved educational interventions for doctors, including online training using email or web pages, short-term interactive educational seminars, short-term field training sessions, and antibiotic guidelines for information dissemination measures, of which 5 studies comprehensively used more than 2 educational interventions. Interventions for doctors also included communication between experts and peers, prescription audit, prescription recommendations, and ranking of doctors' prescription rates in the same department. Among the studies of doctors' interventions, 4 studies involved patients and their families, including the distribution of leaflets and brochures on the rational use of antibiotics, the installation of multimedia education systems in waiting rooms, and the use of flyers and posters. 
Table 2

Categories of interventions included in the 9 studies

\begin{tabular}{|c|c|c|c|c|c|c|c|c|c|c|}
\hline \multirow{2}{*}{\multicolumn{5}{|c|}{ Educational intervention }} & \multirow{4}{*}{ Communication } & \multirow{4}{*}{$\begin{array}{l}\text { Prescription } \\
\text { audit }\end{array}$} & \multirow{4}{*}{$\begin{array}{l}\text { Prescription } \\
\text { recommendations } \\
\text { from expertst }\end{array}$} & \multirow{4}{*}{$\begin{array}{l}\text { Peer } \\
\text { comparison }\end{array}$} & \multicolumn{2}{|c|}{ Patient or family $n$} \\
\hline & & & & & & & & & Brochure & Flyers \\
\hline & \multirow{2}{*}{$\begin{array}{l}\text { Online } \\
\text { training }\end{array}$} & \multirow{2}{*}{$\begin{array}{l}\text { Distribution } \\
\text { of } \\
\text { educational } \\
\text { materials }\end{array}$} & \multicolumn{2}{|c|}{ On-site intervention* } & & & & & & postel \\
\hline & & & $\begin{array}{l}\text { Short- } \\
\text { term } \\
\text { interactive } \\
\text { education } \\
\text { seminar }\end{array}$ & $\begin{array}{l}\text { Short- } \\
\text { term } \\
\text { field } \\
\text { training }\end{array}$ & & & & & & \\
\hline $\begin{array}{l}\text { Dekker } \\
\text { ARJ } \\
(2018)\end{array}$ & $\sqrt{ }$ & & & & & & $\sqrt{ }$ & & $\sqrt{ }$ & \\
\hline $\begin{array}{l}\text { Altiner } \\
\text { A } \\
(2007)\end{array}$ & & & & & $\sqrt{ }$ & & & & & $\sqrt{ }$ \\
\hline $\begin{array}{l}\text { Llor C } \\
(2018)\end{array}$ & & $\sqrt{ }$ & $\sqrt{ }$ & $\sqrt{ }$ & & & $\sqrt{ }$ & & $\sqrt{ }$ & $\sqrt{ }$ \\
\hline $\begin{array}{l}\text { Meeker } \\
\text { D } \\
(2016)\end{array}$ & $\sqrt{ }$ & & & & & & $\sqrt{ }$ & $\sqrt{ }$ & & \\
\hline $\begin{array}{l}\text { Ferrat E } \\
(2016)\end{array}$ & & & $\sqrt{ }$ & $\sqrt{ }$ & & & & & & \\
\hline $\begin{array}{l}\text { Metlay } \\
\text { JP } \\
(2007)\end{array}$ & & $\sqrt{ }$ & $\sqrt{ }$ & $\sqrt{ }$ & & & $\sqrt{ }$ & & $\sqrt{ }$ & $\sqrt{ }$ \\
\hline $\begin{array}{l}\text { Dyrkorn } \\
\text { R } \\
(2016)\end{array}$ & & & $\sqrt{ }$ & & & & & & & \\
\hline $\begin{array}{l}\text { Wei XL } \\
(2018)\end{array}$ & & $\sqrt{ }$ & & $\sqrt{ }$ & & $\sqrt{ }$ & & & & \\
\hline $\begin{array}{l}\text { Qiu JG } \\
(2016)\end{array}$ & & $\sqrt{ }$ & $\sqrt{ }$ & $\sqrt{ }$ & $\sqrt{ }$ & $\sqrt{ }$ & & & & \\
\hline
\end{tabular}

*On-site intervention is a kind of subgroup analysis of intervention measures in this study, including short-term interactive education seminar or short-term fie which is a type of educational intervention.

†Prescription recommendations are the type of subgroup analysis of interventions in this study, and are recommendations for replacement or non-antibiotic from peer experts.

\section{Risk of bias}

Seven studies were rated as having a low risk of bias while 2 were rated as having a high risk of bias. Figure 2 shows the risk of bias assessment for each criterion. Among the 9 studies, $3^{19,23,25}$ in the "Random Sequence Generation" section were determined to have a high risk of bias as none of them described the sampling method. One study ${ }^{19}$ was identified as having a high risk of bias in the "Other Offsets" section due to a lack of random sampling.

\section{Evaluation of publication bias}

Figure 3 shows an inverted funnel chart, which has poor symmetry and suggests a high level of publication bias.

\section{Meta-analysis}

Figure 4 shows a meta-analysis and forest plot of antibiotic prescription samples. The heterogeneity test showed that the results of antibiotic prescription interventions were significantly different $\left(X^{2}=599.42, P \otimes 0.00001, I^{2}=99 \%\right)$, so a random-effects model was chosen. The results of the combined analysis showed that the risk difference was significant and favored the experimental group $(\mathrm{RD}=-0.12,95 \% \mathrm{Cl}=-0.16,-0.07, \mathrm{P}<0.01)$. The rate of antibiotic prescriptions in these studies significantly decreased after the implementation of feedback intervention. However, as there was significant heterogeneity $\left(l^{2}=\right.$ $99 \%$ ), a sensitivity analysis and subgroup analysis was conducted.

\section{Subgroup analysis}

After the sensitivity analysis, a subgroup analysis was conducted according to the study area, whether it was a multidimensional intervention, and whether the doctors were given prescription recommendations by peer eperts to explore the causes of heterogeneity.

\section{Study area}


Table 3 presents results of the subgroup analysis by study area. The Asian region $\left(I^{2}=0 \%\right)$ showed a low degree of heterogeneity, the Americas region $\left(I^{2}=\right.$ $62 \%)$ showed moderate heterogeneity, while the European region $\left(I^{2}=98 \%\right)$ showed high heterogeneity. Antibiotic prescription rates in Asia, America, and Europe were reduced due to various interventions, and the effectiveness of interventions in Asia was significantly higher than that in other regions.

Table 3

Results of subgroup analysis by study area

\begin{tabular}{|c|c|c|c|c|c|c|c|}
\hline \multirow[t]{2}{*}{ Region } & \multirow[t]{2}{*}{ Number of studies } & \multicolumn{3}{|c|}{ Homogeneity test } & \multicolumn{3}{|l|}{ Effect estimate } \\
\hline & & $x^{2}$ & $\mathbf{P}$ & $\mathbf{I}^{2}$ & $\mathrm{RD}(95 \% \mathrm{Cl})$ & $\mathbf{Z}$ & P-value \\
\hline Asia & 2 & 0.46 & 0.5 & 0 & $-0.21(-0.23,-0.19)$ & 22.02 & $<0.01$ \\
\hline America & 2 & 2.66 & 0.1 & 0.62 & $-0.07(-0.09,-0.05)$ & 6.39 & $<0.01$ \\
\hline Europe & 5 & 171.24 & $\nabla 0.01$ & 0.98 & $-0.10(-0.16,-0.04)$ & 3.16 & 0.02 \\
\hline
\end{tabular}

\section{Intervention mode}

Table 4 shows the results of the subgroup analysis by mode of intervention (on-site vs off-site). Studies involving on-site interventions $\left(I^{2}=0 \%\right)$ showed low heterogeneity, and those with off-site interventions $\left(I^{2}=97 \%\right)$ showed high heterogeneity. Both on-site and off-site interventions reduced the antibiotic prescription rates, and the effects of off-site interventions were significantly larger than on-site interventions. The forest maps of various intervention modes are shown in Figs. 8 and 9.

Table 4

Results of subgroup analysis by intervention mode

\begin{tabular}{|c|c|c|c|c|c|c|c|}
\hline \multirow[t]{2}{*}{ Intervention mode } & \multirow[t]{2}{*}{ Number of studies } & \multicolumn{3}{|c|}{ Homogeneity test } & \multicolumn{3}{|l|}{ Effect estimate } \\
\hline & & $\chi^{2}$ & $\mathbf{P}$ & $1^{2}$ & $\mathrm{RD}(95 \% \mathrm{Cl})$ & z & P-value \\
\hline On-site & 2 & 0.78 & 0.38 & 0 & $-0.03(-0.03,-0.02)$ & 15.46 & $<0.01$ \\
\hline Off-site & 7 & 239.72 & $\varangle 0.01$ & 0.97 & $-0.15(-0.20,-0.09)$ & 5.47 & $<0.01$ \\
\hline
\end{tabular}

\section{Prescription recommendations by experts}

Table 5 shows the results of the subgroup analysis by prescription recommendations. Studies in which the doctors were given prescription recommendations from peer experts $\left(I^{2}=47 \%\right)$ showed low heterogeneity, while studies in which doctors were not given prescription recommendations $\left(I^{2}=98 \%\right)$ were highly heterogeneous. Antibiotic prescription rates and the intervention effect for interventions in which the doctors were given prescription recommendations were significantly higher than those that were not. A forest map for grouping prescriptions is shown in Figs. 10 and 11.

Table 5

Results of subgroup analysis by prescription recommendation by experts

\begin{tabular}{|c|c|c|c|c|c|c|c|}
\hline \multirow[t]{2}{*}{ Doctor's behavior } & \multirow[t]{2}{*}{ Number of studies } & \multicolumn{3}{|c|}{ Homogeneity test } & \multicolumn{3}{|l|}{ Effect estimate } \\
\hline & & $\chi^{2}$ & $\mathbf{P}$ & $\mathbf{I}^{\mathbf{2}}$ & $\mathrm{RD}(95 \% \mathrm{Cl})$ & $\mathbf{Z}$ & P-value \\
\hline Prescription recommendations & 4 & 5.65 & 0.13 & $47 \%$ & $-0.08(-0.08,-0.07)$ & 20.17 & $<0.01$ \\
\hline No prescription recommendations & 5 & 478.93 & $\otimes 0.01$ & $99 \%$ & $-0.15(-0.27,-0.03)$ & 2.49 & 0.01 \\
\hline
\end{tabular}

\section{Discussion}

Antibiotics are one of the most widely used drugs in the world. The utilization rate of antibiotics is an important indicator to judge whether medical staff use drugs appropriately. The misuse of antibiotics will not only damage the health of patients, but also cause a huge waste of medical resources ${ }^{26}$. Therefore, while maintaining policy continuity, the health sector should further regulate the use of antibiotics in medical institutions, improve medical facilities and equipment, optimize the overall medical level, and curb the misuse of antibiotics at the source. At the same time, it is also necessary to improve training and education policies for medical personnel, encourage doctors to learn more relevant theoretical knowledge, improve the level of medical technology, and strengthen the understanding of the use of antibiotics in order to reduce the rate of misuse of antibiotics. Medical institutions should provide more lectures on the health knowledge of the harms of antibiotic misuse and publicize the harms of antibiotic misuse and other relevant knowledge, so that patients and their families can also deepen their understanding of antibiotics, strictly follow the doctor's advice for medication, and reduce the amount of antibiotics used by themselves. It is hoped that through our research, some effective measures for antibiotic prescription control will be proposed to future researchers.

This study systematically evaluated the intervention measures of antibiotic prescription rates and their implementation effect in 9 relevant studies. The metaanalysis results showed that the antibiotic prescribing rate of the pre-group antibiotic intervention was significantly lower than that of the control group (RD = $-0.12,95 \% \mathrm{Cl}=-0.16,-0.07, \mathrm{P}<0.01)$. Results of the meta-analysis showed a high degree of heterogeneity $\left(\mathrm{I}^{2}=99 \%\right)$, thus the results could not be combined, Therefore, subgroup analyses were conducted to explore the reasons for the heterogeneity. Although subgroup analysis showed that heterogeneity could be 
partially eliminated by grouping at different levels, many studies still showed high heterogeneity. This suggests that interventions may also have more complex implicit influencing factors or interactions.

From the subgroup analysis by study area, the impact of the intervention was greatest in Asian countries, with a significant reduction in antibiotic prescription rates. Qiu ${ }^{25}$ and $\mathrm{Wei}^{27}$ used a similar multivariate feedback intervention (Table 2) while the European studies were highly heterogeneous. Among them, the study of Dyrkorn from Norway $(\mathrm{RD}=0.00,95 \% \mathrm{Cl}=-0.06,0.05)$ showed that the effect of the intervention on antibiotic prescription rates was not significant ${ }^{23}$ That study recruited physicians to conduct a peer education program on antibiotic prescribing for respiratory infections. The program consisted of three 45 minute interactive educational sessions for the intervention group to learn national guidelines. Compared to the control group, the intervention group followed the national guidelines more, the antibiotic utilization rate of penicillin $\mathrm{V}$ increased and the utilization rate of macrolides decreased, but there was no significant difference in the total antibiotic prescription rate between the intervention group and the control group. The other study was conducted by Ferrat $\mathrm{E}^{21}$ in France. Due to the large sample size, we conducted a sensitivity analysis on the two articles from Europe $\left(\mathrm{I}^{2}\right.$ was reduced from $\left.99-0 \%\right)$. Both of these articles adopted on-site intervention measures, so we divided the 9 sudies into the two subgroups: whether or not they used on-site interventions.

From the subgroup analysis by intervention mode, the reduction of antibiotic prescription rates in studies using off-site interventions was significantly greater than that among studies using in-site interventions. This may be explained by the short intervention duration implemented in the two studies by Dyrkorn ${ }^{23}$ and Ferrat ${ }^{21}$ ( 1 day and 2 days respectively), although the duration of data collection was 2 years and 4 months, and 4 years and 6 months, respectively. Although the effects of the intervention were significant, whether these effects were caused by the intervention would be difficult to determine. The Llor ${ }^{19}$ study also found little or no effect on prescribing behavior over a short period of time for physicians to provide antibiotic education materials, prescription audits, and prescription recommendations. Therefore, the effect of single or short-term intervention on doctors was limited, and long-term and diversified interventions were needed to effectively reduce the prescription rates of antibiotics.

The effect of interventions in which doctors were given prescription recommendations by peer experts was better than not those in which doctors were not given prescription recommendations, and the reduction in antibiotic prescribing rates was statistically significant for this subgroup.

In summary, multiple feedback interventions were used in most of the included studies. Therefore, the hospitals should strengthen the education and training related to antibiotic prescribing behaviors of doctors, and organize medical staff to delve deep into the rules and regulations of antibiotics, and make full use of pharmacology, pharmacokinetics, pharmacodynamics, and other relevant knowledge to issue prescriptions ${ }^{28,29}$. On this basis, various feedback interventions can be added, such as communication between experts and peers, prescription audits, and ranking of doctors in the same department. In addition, interventions can improve the awareness of patients and their families toward antibiotics, such as providing them with brochures and leaflets, displaying posters in the waiting rooms, installing a multimedia education system in wating areas, and encouraging patients to communicate more with their physicians about the use of antibiotics. Dekker ${ }^{17}$, Llor ${ }^{19}$, and Metlay ${ }^{22}$ adopted certain intervention measures for patients and their families based on educational intervention measures for medical staff. Altiner ${ }^{18}$ intervened patients and their families based on using feedback intervention for medical staff, and the degree of reduction of antibiotic utilization was significantly higher than other studies. Therefore, according to education and training interventions, feedback interventions were used to influence the prescribing behavior of doctors and improve the cognition of patients and their families about antibiotics. This multivariate behavioral feedback intervention might be a more rational approach to antibiotic prescription control. In terms of policymaking, health administration departments should introduce laws, regulations, and relevant policies on the administration of antibiotics to strictly control the use of antibiotics. These departments can take strong administrative interventions against the unreasonable use of antibiotics, for example, patients or consumers could only obtain antibiotics from the pharmacies based on prescriptions, and doctors can prescribe antibiotics in a hierarchical manner.

Our study has certain limitations. First, only nine studies could be included, therefore there is a possibility of publication bias. However, some studies were not included due to incomplete data. Thislimitations may have reduced the objectivity of the results to a certain extent. Second, there are different degrees of quality differences in the design of the included studies, which may have affected our results. Third, the nine studies were conducted in 7 countries. The policies and management systems of antibiotic use are different among countries, thus there was a risk of information bias. Lastly, there was still a high degree of heterogeneity of some data in the subgroup analyses indicating that there were still other unknown factors affecting the results.

\section{Conclusion}

This study found that implementing feedback interventions in hospitals can effectively reduce antibiotic prescription rates and promote the rational use of antibiotics. However, due to the above limitations, we can only prove that adding multiple feedback interventions to education interventions may be a more reasonable control method. In the future, more studies need to be included to obtain more accurate information.

\section{Abbreviations}

CENTRAL: Cochrane Central Register of Controlled Trials;

ATB: Antibiotics;

CNKI: Chinese Journal Full-text;

RD: Risk difference;

Cl: Confidence interval; 
RCTs: Randomized Controlled Trials;

RTIs: Respiratory tract infections

\section{Declarations}

\section{Conflict of Interest}

All authors have no conflicts of interest to declare.

\section{Consent for publication}

Not applicable.

\section{Availability of data and materials}

Not applicable.

\section{Authors' contributions}

All authors made substantial contributions to the development of the trial, and read and approved the final manuscript. YC, ZZC, GHY designed the trial. XZ drafted the manuscript, and YC and ZZC completed data extraction, statistical analysis and data interpretation. GHY and LT participated in the concept, data interpretation and manuscript revision. YC is responsible for data integrity and accuracy of data analysis.

\section{Acknowledgments}

We thank all of the participating institutions for providing information and assistance during the study. The authors also thank all members of the investigational team who collected the data.

This study was due to a grant obtained from the National Natural Science Foundation of China Grant on "Research on feedback intervention mode of antibiotic prescription control in primary medical institutions based on the depth graph neural network technology" (71964009) and the Science and Technology Fund Project of Guizhou Provincial Health Commission Grant on "Application Research of Deep Learning Technology in Rational Evaluation and Intervention of Antibiotic Prescription" (gzwjkj2019-1-218).

\section{Funding}

The study was funded by the National Natural Science Foundation of China Grant on "Research on feedback intervention mode of antibiotic prescription control in primary medical institutions based on the depth graph neural network technology" (71964009) and the Science and Technology Fund Project of Guizhou Provincial Health Commission Grant on "Application Research of Deep Learning Technology in Rational Evaluation and Intervention of Antibiotic Prescription" (gzwjkj2019-1-218).

\section{Ethical approval}

This study was approved by the Academic Committee of Guizhou Medical University. All participants provided written informed consent

\section{References}

1. World Health Organization. Global antimicrobial resistance surveillance system (GLASS) report 2017-2018. 2018.1. Organization WH. Global antimicrobial resistance surveillance system (GLASS) report 2017-2018. 2018.

2. World Health Organization. Antimicrobial Resistance Global Report on surveillance 2014. World Health Organization 2014.

3. World Health Organization. Antibiotic prescribing and resistance: Views from low- and middle-income prescribing and dispensing professionals. 2017.

4. Bush K, Courvalin P, Dantas G, Davies J, Eisenstein B, Huovinen P, et al. Tackling antibiotic resistance. Nature Reviews Microbiology 2011;9(12):894-6.

5. Hemkens LG, Saccilotto R, Reyes SL, Glinz D, Zumbrunn T, Grolimund O, et al. Personalized Prescription Feedback Using Routinely Collected Data to Reduce Antibiotic Use in Primary Care A Randomized Clinical Trial. Jama Internal Medicine 2017;177(2):176-83.

6. Hillier S, Roberts Z, Dunstan F, Butler C, Howard A, Palmer S. Prior antibiotics and risk of antibiotic-resistant community-acquired urinary tract infection: a case-control study. J Antimicrob Chemother 2007;60(1):92-9.

7. Butler CC, Dunstan F, Heginbothom M, Mason B, Roberts Z, Hillier S, et al. Containing antibiotic resistance: decreased antibiotic-resistant coliform urinary tract infections with reduction in antibiotic prescribing by general practices. Br J Gen Pract 2007;57(543):785-92.6-8区.

8. Davey P, Marwick CA, Scott CL, Charani E, McNeil K, Brown E, et al. Interventions to improve antibiotic prescribing practices for hospital inpatients. Cochrane Database Syst Rev 2017;2:CD003543.

9. Janet EH, Michele P, Donald DeBoer. Confidential prescriber feedback and education to improve antibiotic use in primary care: a controlled trial. Canadian Medical Association Journal August 24, 1999161 (4) 388-92.

10. Elouafkaoui P, Young L, Newlands R, Duncan EM, Elders A, Clarkson JE, et al. An Audit and Feedback Intervention for Reducing Antibiotic Prescribing in General Dental Practice: The RAPiD Cluster Randomised Controlled Trial. PLoS Med 2016;13(8):e1002115. 
11. Freedberg DE, Salmasian H, Abrams JA, Green RA. Orders for Intravenous Proton Pump Inhibitors After Implementation of an Electronic Alert. Jama Internal Medicine 2015;175(3):452-4.

12. Hallsworth M, Chadborn T, Sallis A, Sanders M, Berry D, Greaves F, et al. Provision of social norm feedback to high prescribers of antibiotics in general practice: a pragmatic national randomised controlled trial. Lancet 2016;387(10029):1743-52.

13. Kandel CE, Gill S, McCready J, Matelski J, Powis JE. Reducing co-administration of proton pump inhibitors and antibiotics using a computerized order entry alert and prospective audit and feedback. BMC Infect Dis 2016;16:355.

14. Tamma PD, Avdic E, Keenan JF, Zhao Y, Anand G, Cooper J, et al. What Is the More Effective Antibiotic Stewardship Intervention: Preprescription Authorization or Postprescription Review With Feedback? Clin Infect Dis 2017;64(5):537-43.

15. Moher D, Liberati A, Tetzlaff J, Altman DG, Group P. Preferred reporting items for systematic reviews and meta-analyses: the PRISMA statement. PLoS Med 2009;6(7):e1000097.

16. West China hospital of Sichuan University, Center for China Cochrane, Evidence-based medicine center of Lanzhou University. Handbook for systematic evaluation of interventions- Cochrane. 2014.

17. Dekker ARJ, Verheij TJM, Broekhuizen BDL, Butler CC, Cals JWL, Francis NA, et al. Effectiveness of general practitioner online training and an information booklet for parents on antibiotic prescribing for children with respiratory tract infection in primary care: a cluster randomized controlled trial. $\mathrm{J}$ Antimicrob Chemother 2018;73(5):1416-22.

18. Altiner A, Brockmann S, Sielk M, Wilm S, Wegscheider K, Abholz HH. Reducing antibiotic prescriptions for acute cough by motivating GPs to change their attitudes to communication and empowering patients: a cluster-randomized intervention study. Journal of Antimicrobial Chemotherapy 2007;60(3):63844.

19. Llor C, Bjerrum L, Molero JM, Moragas A, Lopez-Valcarcel BG, Monedero MJ, et al. Long-term effect of a practice-based intervention (HAPPY AUDIT) aimed at reducing antibiotic prescribing in patients with respiratory tract infections. Journal of Antimicrobial Chemotherapy 2018;73(8):2215-22.

20. Meeker D, Linder JA, Fox CR, Friedberg MW, Persell SD, Goldstein NJ, et al. Effect of Behavioral Interventions on Inappropriate Antibiotic Prescribing Among Primary Care Practices: A Randomized Clinical Trial. JAMA 2016;315(6):562-70.

21. Ferrat E, Le Breton J, Guery E, Adeline F, Audureau E, Montagne O, et al. Effects 4.5 years after an interactive GP educational seminar on antibiotic therapy for respiratory tract infections: a randomized controlled trial. Fam Pract 2016;33(2):192-9.

22. Metlay JP, Camargo CA, MacKenzie T, McCulloch C, Maselli J, Levin SK, et al. Cluster-randomized trial to improve antibiotic use for adults with acute respiratory infections treated in emergency departments. Annals of Emergency Medicine 2007;50(3):221-30.

23. Dyrkorn R, Gjelstad S, Espnes KA, Lindbaek M. Peer academic detailing on use of antibiotics in acute respiratory tract infections. A controlled study in an urban Norwegian out-of-hours service. Scandinavian Journal of Primary Health Care 2016;34(2):180-5.

24. Wei X, Zhang Z, Hicks JP, Walley JD, King R, Newell JN, et al. Long-term outcomes of an educational intervention to reduce antibiotic prescribing for childhood upper respiratory tract infections in rural China: Follow-up of a cluster-randomised controlled trial. PLoS Med 2019;16(2):e1002733.

25. Qiu JG. Clinical application of antibiotics in respiratory medicine and the significance of pharmaceutical intervention. Chinese medicine guide 2016;14(21):105-6.

26. Li X, Zeng J, Wang D, Xue YX, Zhao XL. Recent advances in the mechanism of bacterial drug resistance. Chinese journal of antibiotics 2020; 45 (02):11321.

27. Wei XL, Zhang ZT, Walley JD, Hicks JP, Zeng J, Deng SM, et al. Effect of a training and educational intervention for physicians and caregivers on antibiotic prescribing for upper respiratory tract infections in children at primary care facilities in rural China: a cluster-randomised controlled trial. Lancet Global Health 2017;5(12):E1258-67.

28. Luo M, Wei SB, Huang L, Chen W, Zhang YH. Systematic evaluation and meta-analysis of KangFu anti-inflammatory suppository combined with antibiotics in the treatment of pelvic inflammatory disease. Chinese journal of antibiotics 2019;44(04):519-26.

29. Tang YQ, Du X, Wang HT, Yang LP, Zhang XP. Meta-analysis of the effect of comprehensive intervention on reducing the utilization rate of antibiotics in hospitalized patients. China Pharmacy 2013;24(24):2275-9.

\section{Figures}




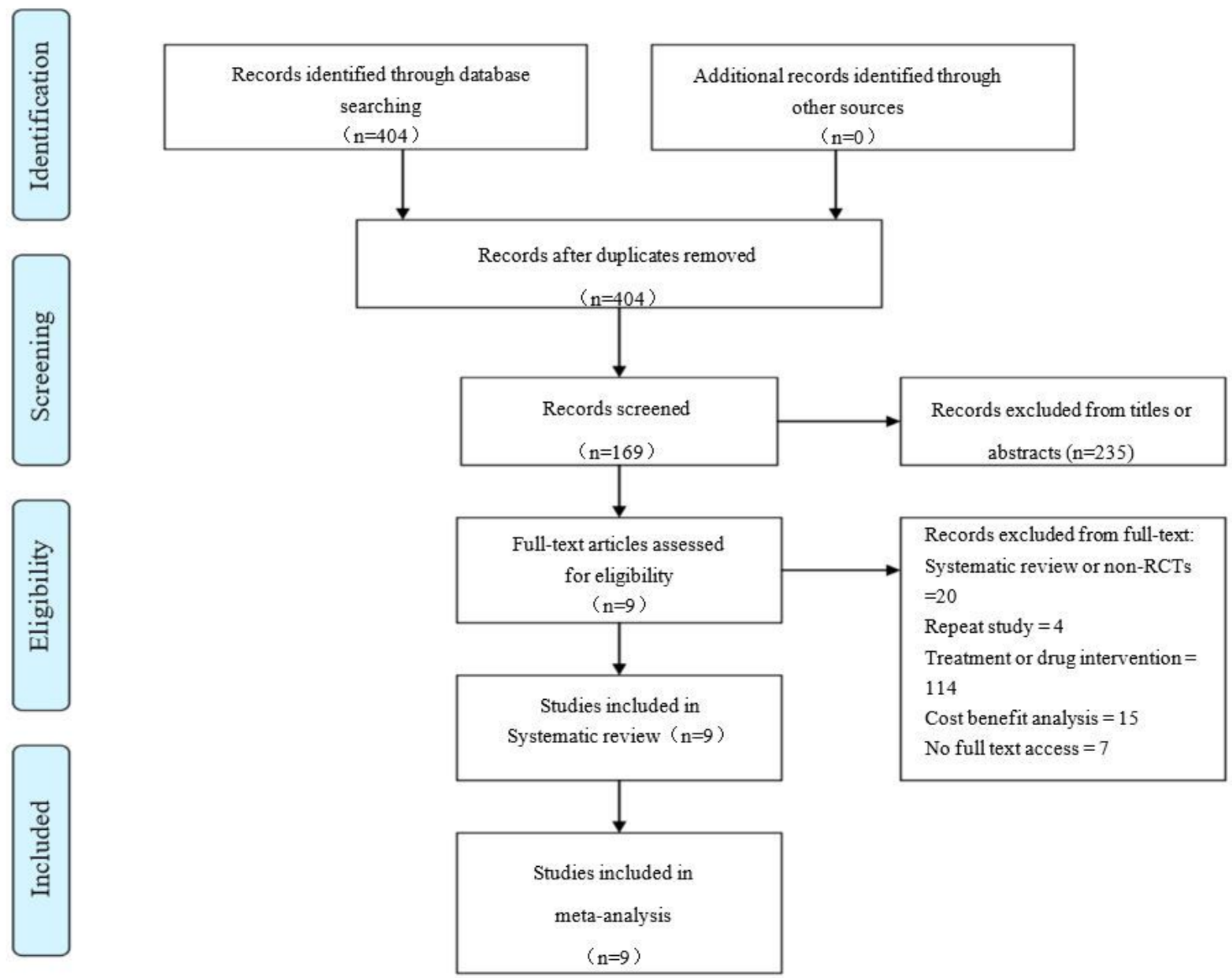

Figure 1

PRISMA screening flow chart 


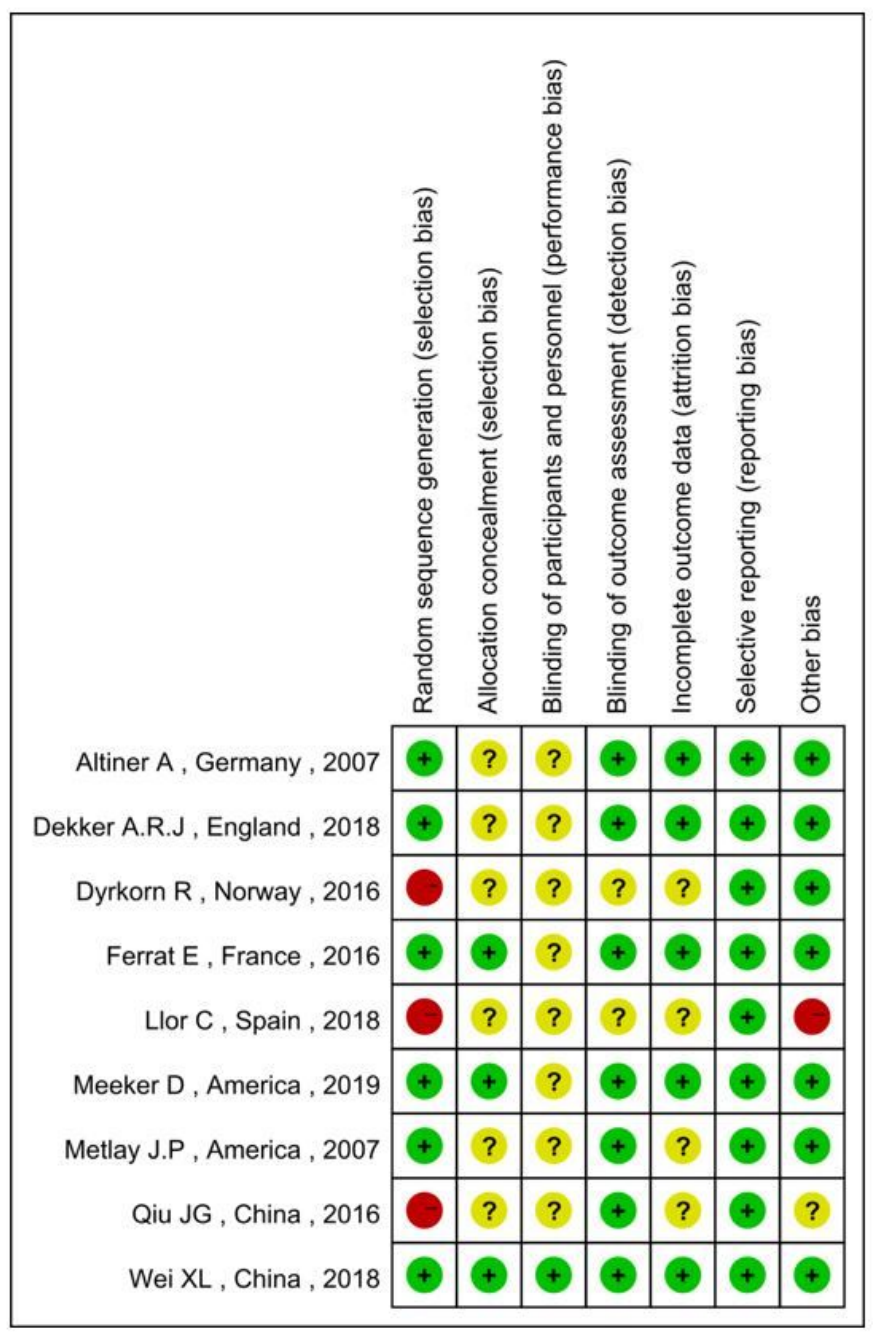

Figure 2

Risk of bias summary

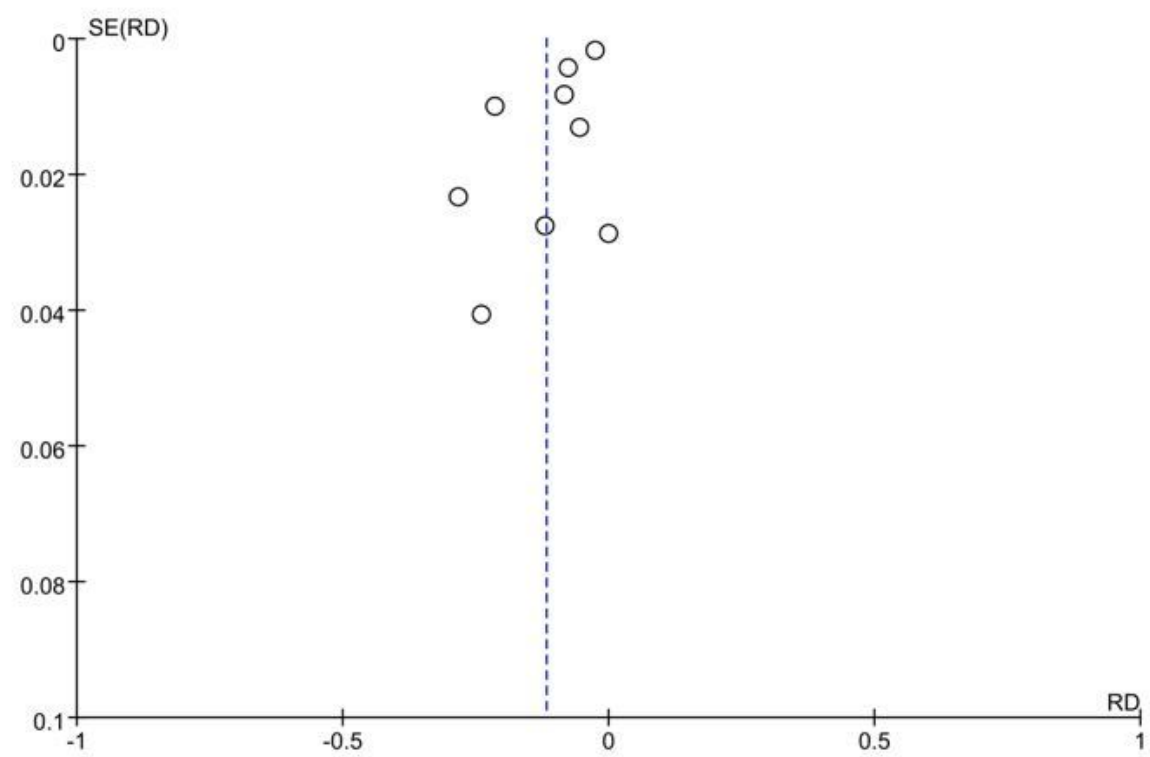

Figure 3

Inverted funnel plot of the effects of interventions on doctors' antibiotic prescription rates

Page $11 / 15$ 


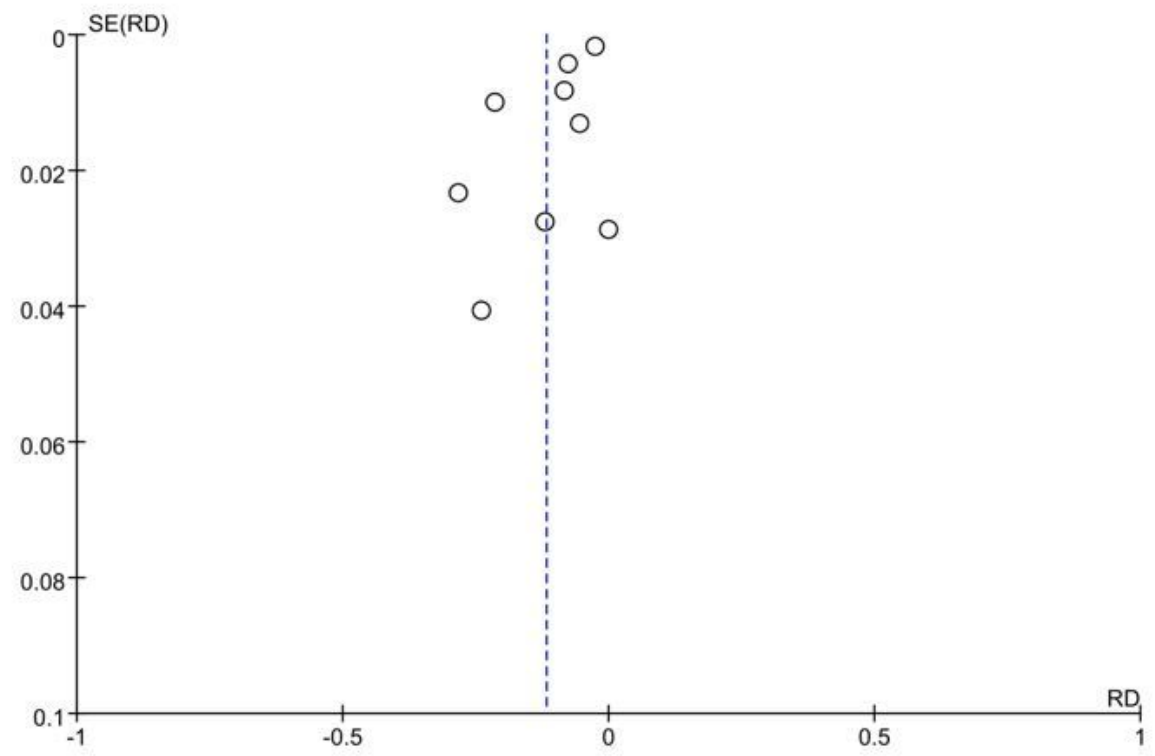

Figure 3

Inverted funnel plot of the effects of interventions on doctors' antibiotic prescription rates

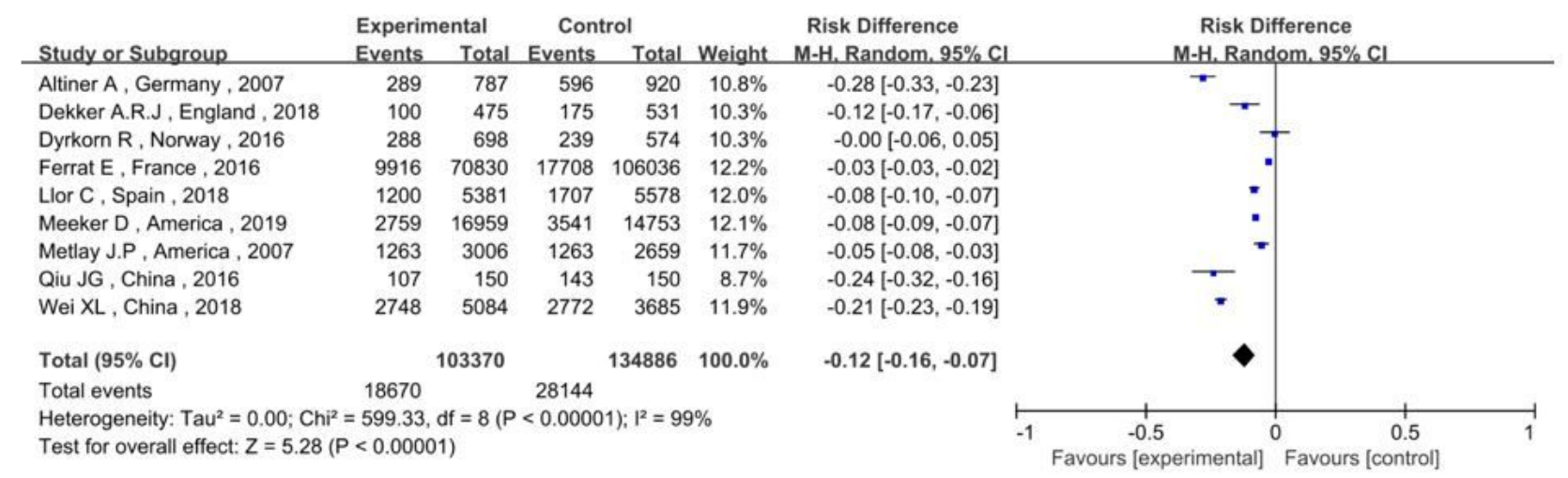

Figure 4

Meta-analysis results and forest plot of antibiotic prescription rates for 9 studies

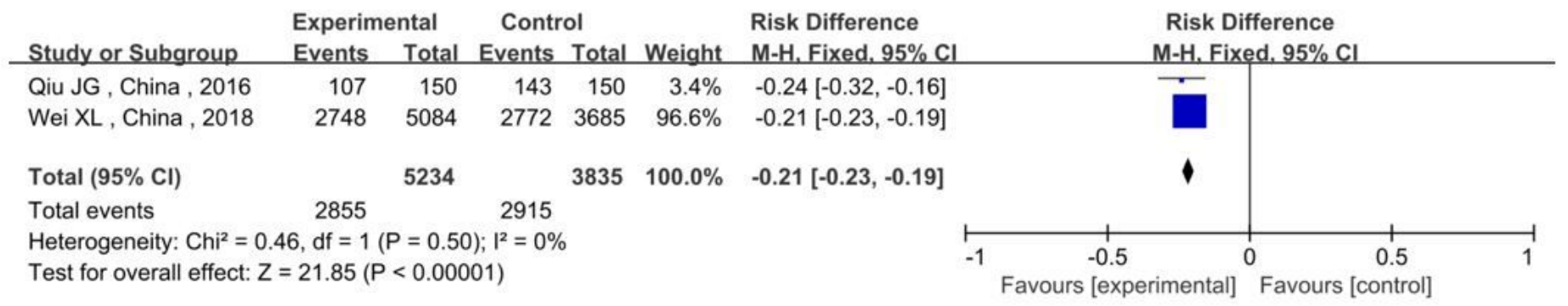

\section{Figure 5}

ThMeta-analysis and forest plot of antibiotic prescription rates in Asia 


\begin{tabular}{|c|c|c|c|c|c|c|c|c|c|}
\hline \multirow[b]{2}{*}{ Study or Subgroup } & \multicolumn{2}{|c|}{ Experimental } & \multicolumn{2}{|c|}{ Control } & \multirow[b]{2}{*}{ Weight } & \multirow{2}{*}{$\begin{array}{l}\text { Risk Difference } \\
\text { M-H. Random, } 95 \% \mathrm{Cl}\end{array}$} & \multirow{2}{*}{\multicolumn{3}{|c|}{$\begin{array}{c}\text { Risk Difference } \\
\text { M-H. Random. } 95 \% \mathrm{Cl}\end{array}$}} \\
\hline & Events & Total & Events & Total & & & & & \\
\hline Meeker D , America , 2019 & 2759 & 16959 & 3541 & 14753 & $64.9 \%$ & $-0.08[-0.09,-0.07]$ & & & \\
\hline Metlay J.P , America , 2007 & 1263 & 3006 & 1263 & 2659 & $35.1 \%$ & $-0.05[-0.08,-0.03]$ & - & & \\
\hline Total $(95 \% \mathrm{Cl})$ & & 19965 & & 17412 & $100.0 \%$ & $-0.07[-0.09,-0.05]$ & $\downarrow$ & & \\
\hline Total events & 4022 & & 4804 & & & & & & \\
\hline Heterogeneity: Tau $^{2}=0.00 ;$ & $\mathrm{i}^{2}=2.66$, & $\mathrm{df}=1(\mathrm{~F}$ & $=0.10)$ & $1^{2}=62 \%$ & & & -0.5 & 0.5 & 1 \\
\hline Test for overall effect: $Z=6$. & $(P<0.0$ & 001) & & & & & Favours [experimental] & Favours [control] & \\
\hline
\end{tabular}

\section{Figure 6}

Meta-analysis and forest plot of antibiotic prescription rates in the Americas

\begin{tabular}{|c|c|c|c|c|c|c|c|c|c|}
\hline \multirow[b]{2}{*}{ Study or Subgroup } & \multicolumn{2}{|c|}{ Experimental } & \multicolumn{2}{|c|}{ Control } & \multirow[b]{2}{*}{ Weight } & \multirow{2}{*}{$\begin{array}{c}\text { Risk Difference } \\
\text { M-H. Random. } 95 \% \mathrm{Cl}\end{array}$} & \multirow{2}{*}{\multicolumn{3}{|c|}{$\begin{array}{c}\text { Risk Difference } \\
\text { M-H. Random. } 95 \% \mathrm{Cl}\end{array}$}} \\
\hline & Events & Total & Events & Total & & & & & \\
\hline Meeker D , America , 2019 & 2759 & 16959 & 3541 & 14753 & $64.9 \%$ & $-0.08[-0.09,-0.07]$ & & & \\
\hline Metlay J.P, America , 2007 & 1263 & 3006 & 1263 & 2659 & $35.1 \%$ & $-0.05[-0.08,-0.03]$ & - & & \\
\hline Total $(95 \% \mathrm{CI})$ & & 19965 & & 17412 & $100.0 \%$ & $-0.07[-0.09,-0.05]$ & 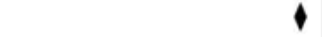 & & \\
\hline Total events & 4022 & & 4804 & & & & & & \\
\hline Heterogeneity: $\operatorname{Tau}^{2}=0.00$; & $i^{2}=2.66$ & $\mathrm{df}=1$ & $=0.10)$ & $I^{2}=62^{\circ}$ & & & $\begin{array}{ll}1 & 1 \\
-1 & -0.5\end{array}$ & 0.5 & 1 \\
\hline Test for overall effect: $Z=6$. & $(P<0.0$ & $001)$ & & & & & Favours [experimental] & Favours [control] & \\
\hline
\end{tabular}

\section{Figure 6}

Meta-analysis and forest plot of antibiotic prescription rates in the Americas

\begin{tabular}{|c|c|c|c|c|c|c|c|c|c|}
\hline \multirow[b]{2}{*}{ Study or Subgroup } & \multicolumn{2}{|c|}{ Experimental } & \multicolumn{2}{|c|}{ Control } & & \multirow{2}{*}{$\begin{array}{l}\text { Risk Difference } \\
\text { M-H. Random, } 95 \% \mathrm{Cl}\end{array}$} & \multirow{2}{*}{\multicolumn{3}{|c|}{$\begin{array}{c}\text { Risk Difference } \\
\text { M-H, Random, } 95 \% \mathrm{Cl}\end{array}$}} \\
\hline & Events & Total & Events & Total & Weight & & & & \\
\hline Altiner A, Germany, 2007 & 289 & 787 & 596 & 920 & $19.5 \%$ & $-0.28[-0.33,-0.23]$ & $=$ & & \\
\hline Dekker A.R.J , England , 2018 & 100 & 475 & 175 & 531 & $18.7 \%$ & $-0.12[-0.17,-0.06]$ & - & & \\
\hline Dyrkorn R, Norway , 2016 & 288 & 698 & 213 & 514 & $18.5 \%$ & $-0.00[-0.06,0.05]$ & & & \\
\hline Ferrat E , France , 2016 & 9916 & 70830 & 17708 & 106036 & $21.8 \%$ & $-0.03[-0.03,-0.02]$ & - & & \\
\hline Llor C , Spain , 2018 & 1200 & 5381 & 1707 & 5578 & $21.5 \%$ & $-0.08[-0.10,-0.07]$ & - & & \\
\hline Total $(95 \% \mathrm{Cl})$ & & 78171 & & 113579 & $100.0 \%$ & $-0.10[-0.16,-0.04]$ & & & \\
\hline Total events & 11793 & & 20399 & & & & & & \\
\hline Heterogeneity: $\mathrm{Tau}^{2}=0.00 ; \mathrm{Chi}$ & $=171.24$, & $d f=4(P$ & $<0.0000$ & $01) ; 1^{2}=9$ & & & -0.5 & 0.5 & 1 \\
\hline Test for overall effect: $Z=3.16$ & $=0.002)$ & & & & & & Favours [experimental] & Favours [control] & \\
\hline
\end{tabular}

Figure 7

Meta-analysis and forest plot of antibiotic prescription rates in Europe

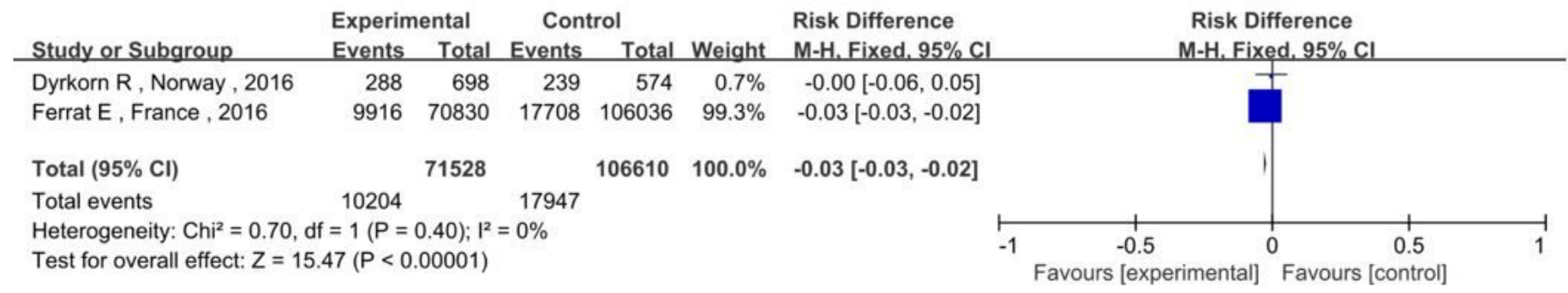

Figure 8

Meta-analysis and forest plot of antibiotic prescription rates in on-site interventions 


\begin{tabular}{|c|c|c|c|c|c|c|c|c|c|}
\hline \multirow[b]{2}{*}{ Study or Subgroup } & \multicolumn{2}{|c|}{ Experimental } & \multicolumn{2}{|c|}{ Control } & \multirow[b]{2}{*}{ Weight } & \multirow{2}{*}{$\begin{array}{l}\text { Risk Difference } \\
\text { M-H. Random, } 95 \% \mathrm{Cl}\end{array}$} & \multirow{2}{*}{\multicolumn{3}{|c|}{$\begin{array}{c}\text { Risk Difference } \\
\text { M-H. Random. } 95 \% \mathrm{Cl}\end{array}$}} \\
\hline & Events & Total & Events & Total & & & & & \\
\hline Altiner A, Germany , 2007 & 289 & 787 & 596 & 920 & $14.0 \%$ & $-0.28[-0.33,-0.23]$ & $=$ & & \\
\hline Dekker A.R.J , England , 2018 & 100 & 475 & 175 & 531 & $13.4 \%$ & $-0.12[-0.17,-0.06]$ & $=$ & & \\
\hline Llor C , Spain , 2018 & 1200 & 5381 & 1707 & 5578 & $15.3 \%$ & $-0.08[-0.10,-0.07]$ & $=$ & & \\
\hline Meeker D , America , 2019 & 2759 & 16959 & 3541 & 14753 & $15.5 \%$ & $-0.08[-0.09,-0.07]$ & - & & \\
\hline Metlay J.P , America , 2007 & 1263 & 3006 & 1263 & 2659 & $15.0 \%$ & $-0.05[-0.08,-0.03]$ & $=$ & & \\
\hline Qiu JG , China , 2016 & 107 & 150 & 143 & 150 & $11.5 \%$ & $-0.24[-0.32,-0.16]$ & $\longrightarrow$ & & \\
\hline Wei XL , China , 2018 & 2748 & 5084 & 2772 & 3685 & $15.3 \%$ & $-0.21[-0.23,-0.19]$ & $=$ & & \\
\hline Total $(95 \% \mathrm{CI})$ & & 31842 & & 28276 & $100.0 \%$ & $-0.15[-0.20,-0.09]$ & & & \\
\hline Total events & 8466 & & 10197 & & & & & & \\
\hline \multicolumn{7}{|c|}{ Heterogeneity: $\mathrm{Tau}^{2}=0.00 ; \mathrm{Chi}^{2}=239.72, \mathrm{df}=6(\mathrm{P}<0.00001) ; \mathrm{I}^{2}=97 \%$} & $\begin{array}{lll}1 & -0.5 & 0\end{array}$ & 0.5 & 1 \\
\hline \multicolumn{7}{|c|}{ Test for overall effect: $Z=5.47(P<0.00001)$} & Favours [experimental] & Favours [control] & \\
\hline
\end{tabular}

Figure 9

Meta-analysis and forest plot of antibiotic prescription rates in off-site interventions

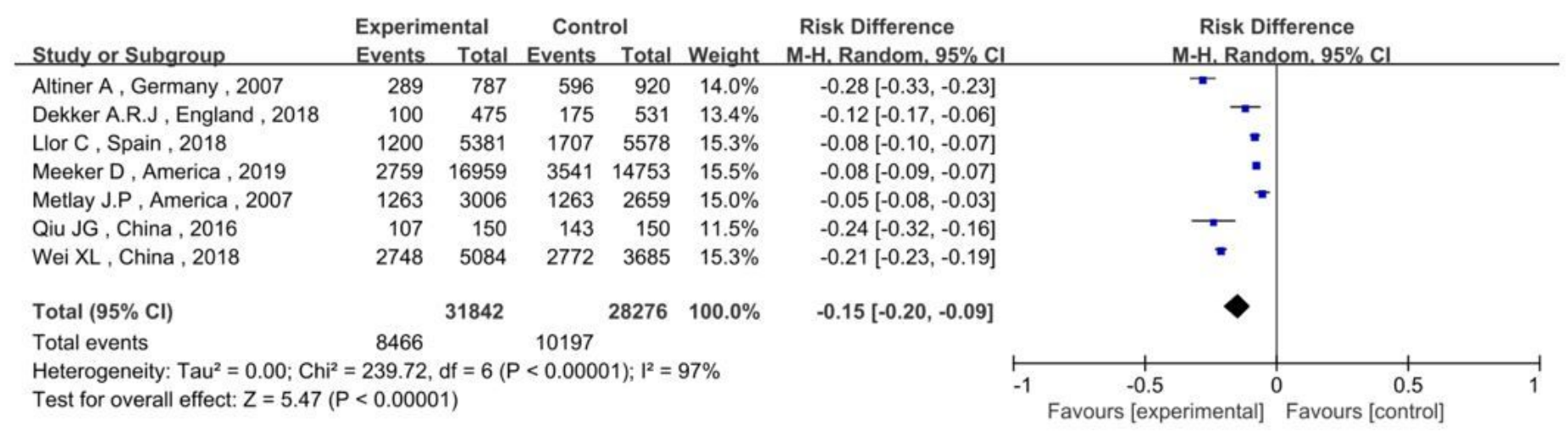

\section{Figure 9}

Meta-analysis and forest plot of antibiotic prescription rates in off-site interventions

\begin{tabular}{|c|c|c|c|c|c|c|c|c|c|}
\hline \multirow[b]{2}{*}{ Study or Subgroup } & \multicolumn{2}{|c|}{ Experimental } & \multicolumn{2}{|c|}{ Control } & \multirow[b]{2}{*}{ Weight } & \multirow{2}{*}{$\begin{array}{l}\text { Risk Difference } \\
\mathrm{M}-\mathrm{H} \text {. Fixed. } 95 \% \mathrm{Cl}\end{array}$} & \multirow{2}{*}{\multicolumn{3}{|c|}{$\begin{array}{c}\text { Risk Difference } \\
\text { M-H. Fixed. } 95 \% \mathrm{Cl}\end{array}$}} \\
\hline & Events & Total & Events & Total & & & & & \\
\hline Dekker A.R.J , England , 2018 & 100 & 475 & 175 & 531 & $2.0 \%$ & $-0.12[-0.17,-0.06]$ & $\rightarrow$ & & \\
\hline Llor C , Spain , 2018 & 1200 & 5381 & 1707 & 5578 & $22.3 \%$ & $-0.08[-0.10,-0.07]$ & - & & \\
\hline Meeker D , America , 2019 & 2759 & 16959 & 3541 & 14753 & $64.2 \%$ & $-0.08[-0.09,-0.07]$ & a & & \\
\hline Metlay J.P , America, 2007 & 1263 & 3006 & 1263 & 2659 & $11.5 \%$ & $-0.05[-0.08,-0.03]$ & $=$ & & \\
\hline Total $(95 \% \mathrm{Cl})$ & & 25821 & & 23521 & $100.0 \%$ & $-0.08[-0.08,-0.07]$ & 1 & & \\
\hline Total events & 5322 & & 6686 & & & & & & \\
\hline Heterogeneity: $\mathrm{Chi}^{2}=5.65, \mathrm{df}=$ & $(P=0.13$ & $; 1^{2}=47$ & & & & & \begin{tabular}{|ll}
-1 & -0.5 \\
\end{tabular} & $0 \quad 0.5$ & 1 \\
\hline Test for overall effect: $Z=20.17$ & $P<0.000$ & & & & & & Favours [experimental] & Favours [control] & \\
\hline
\end{tabular}

\section{Figure 10}

Meta-analysis and forest plot of antibiotic prescription rates in studies involving doctors receiving prescription advice from peer expert 
from peer expert

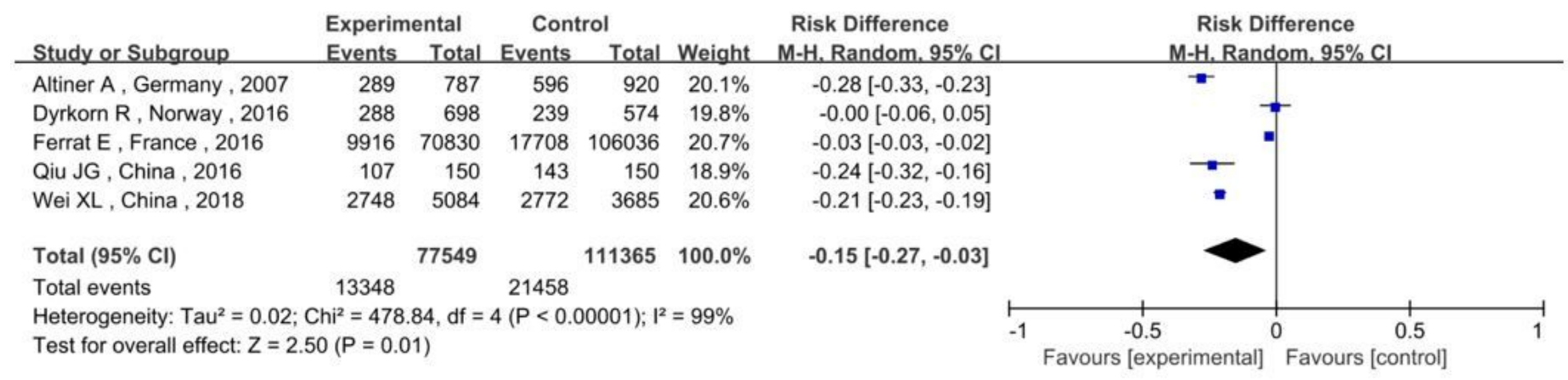

\section{Figure 11}

Meta-analysis and forest plot of antibiotic prescription rates in studies involving doctors not receiving prescription advice from peer experts

$$
\text { from peer expert }
$$

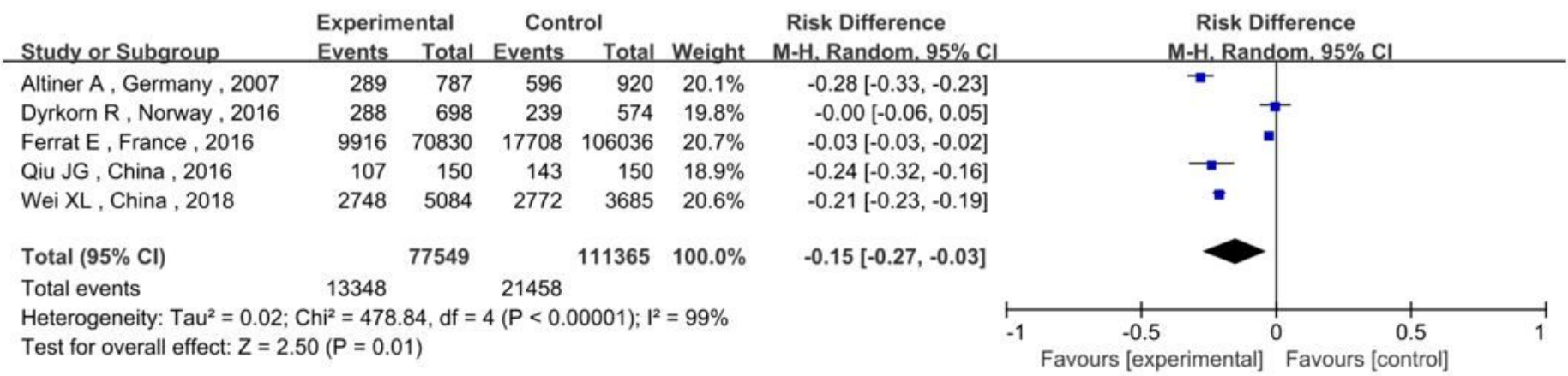

\section{Figure 11}

Meta-analysis and forest plot of antibiotic prescription rates in studies involving doctors not receiving prescription advice from peer experts

\section{Supplementary Files}

This is a list of supplementary files associated with this preprint. Click to download.

- PRISMA2009checklistChang.doc 